\title{
Fracture Toughness of Multi Walled Carbon Nano Tubes Modfied Polymer Composite in Mode - I
}

\author{
J. V. Sai Prasanna Kumar ${ }^{1}$, G. Raghava ${ }^{2} \&$ A. Joseph Stanley ${ }^{3}$ \\ ${ }^{1}$ Anna University, Chennai, India \\ ${ }^{2}$ CSIR-SERC, Fatigue \& Fracture Lab, Chennai, India \\ ${ }^{3}$ Hindustan University, Padur, India \\ Correspondence: J. V. Sai Prasanna Kumar, Anna University, Chennai, India. Tel: 91-979-110-5224. E-mail: \\ kumargsaiprasannajv@yahoo.co.in
}

Received: May 21, 2012 Accepted: June 19, 2012 Online Published: June 28, 2012

doi:10.5539/jmsr.v1n3p117 URL: http://dx.doi.org/10.5539/jmsr.v1n3p117

\begin{abstract}
In the present work Multi Walled Carbon Nano Tubes were dispersed into Ly 566 with $1 \%, 3 \%$ and 5\% by weight and nano composites were manufactured using the wet-layup technique in two different stacking sequences namely $0 / 90$ and $0 / 0$. For the dispersion of the nano tubes into the polymer an ultra sonic bath was utilized to sonicate the Multi Walled Carbon Nano Tubes. The property fracture toughness has been characterized by a using standard double cantilever beam (DCB) specimen to estimate the fracture parameter namely $\mathrm{G}_{\mathrm{IC}}$. According to the tests the nano tube filling of the matrix of the composites has a beneficial effect on their interlaminar properties and the strain energy release rate increased significantly over the virgin samples. The broken fracture surfaces of the failed samples were examined with a high resolution scanning electron microscope.
\end{abstract}

Keywords: MWNT, Fracture toughness, DCB, Mode-I, SEM Images

\section{Introduction}

Delamination of the fiber reinforced composite laminate can significantly weaken the composite structure particularly during impact loading (Gilbert et al., 2003; Mouritz et al., 1999). There are three different fracture modes of delamination including opening mode (Mode-I), sliding mode (Mode-II) and scissoring shear mode (Mode-III). Several approaches have used to increase the delamination resistance. A well known approach to inhibit the delamination is to manufacture the fiber perform using advanced textile technologies of knitting, braiding, stitching and weaving. Along with crack branching, delamination was forced to follow a meandering path due to improved interlaminar fracture toughness. The delamination resistance of the composite laminate can also be affected by the alignment of fibers. Analysis using 3D finite element models showed a $10-40 \%$ increase in $\mathrm{G}_{\mathrm{IC}}$ (critical strain energy release rate of mode-I) for multi directional laminates with interfaces of 0/90, 0/45 and 45/-45 over the 0/0 laminates (Morais, 2003). These results were experimentally confirmed using double cantilever beam (DCB) tests.

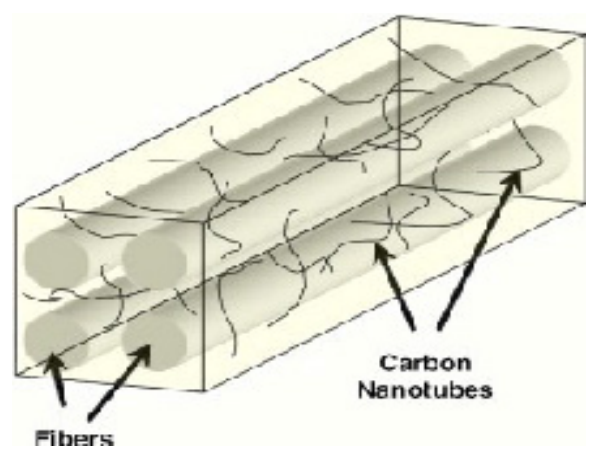

Figure 1. A Schematic representation of nano tubes penetration in between the fibers 
Many studies show that utilization filler particles in the interlayer can also increase the Mode-I delamination resistance of fiber reinforced polymer composites. The infusion of nanoclay and rubber into the polymer (Fielding \& Jacques, 2004; Majid et al., 2011) shows a promise for improving $\mathrm{G}_{\mathrm{IC}}$ (Figure 1). Carbon nano tubes are potential fullers to be used in polymer matrix since the carbon nano tubes have excellent mechanical, electrical, and thermal properties (Robinson et al., 1999; Kim et al., 2001). Due to their small diameter they may affect the properties of polymer composite at the molecular level. However, due to manufacturing challenges (Fan et al., 2004) the full potential of the nano tubes have not been realized. Fiedler (Fiedler et al., 2004) have reported that by adding 0.3 weight per cent of Double Walled Carbon Nano Tubes an increase of interlaminar shear strength by $20 \%$ was obtained and they found that this trend was in agreement with other reports (Hasio et al., 2003; Meguid et al., 2004).

The purpose of this paper is to investigate the influence on Mode-I delamination when Multi Walled Carbon Nano Tubes are added to continuous fiber reinforced polymer composites. The critical strain energy release rate of the virgin samples in Mode-I was compared with the values of the strain energy release rate of the samples infused with MWNT in various percentages.

\section{Experiment}

\subsection{Composite Specimen Fabrication}

Vapor grown multi walled carbon nano tubes obtained from M/S Nanoshell, Haryana had $0.4 \%$ amorphous carbon, metallic impurities were dispersed into Ly 566 obtained from M/S Araldite using a three stage process. First: the multi walled carbon nano tubes were heated in muffle furnace for $400^{\circ} \mathrm{C}$ for four hours to remove the amorphous carbon. Then these tubes were added to dilute nitric acid and were magnetically stirred for an hour. Multi walled carbon nano tubes were rinsed with distilled water and then heated in an oven for $80^{\circ} \mathrm{C}$ to remove moisture content.

Second: the multi walled carbon nano tubes were added to toluene again the suspension was sonicated in ultra sonicator bath for thirty minutes.

Third: this suspension was added to appropriate amount of epoxy resin (Figure 2) and it was sonicated for an hour. Finally this suspension was heated to $80^{\circ} \mathrm{C}$ remove the presence of toluene.

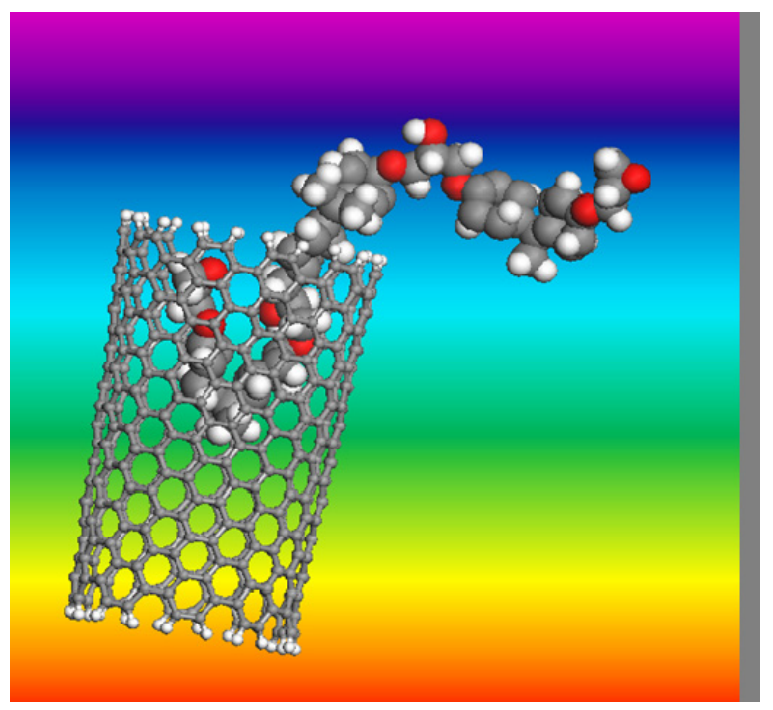

Figure 2. Schematic representation of dispersing MWNT into epoxy

Wet layup process was used for impregnating the stiched woven E-glass rovings. Initially a $3 \mathrm{~mm}$ thick aluminum plate with $350 \mathrm{~mm} \times 350 \mathrm{~mm}$ dimensions was cleaned thoroughly with acetone and a silicone based release agent was applied on the aluminum mold to facilitate the easy removal of the part from the mold. The woven rovings were laid on the mold and a coat of resin was applied. The excess resin was gently squeezed out. This process was repeated till the desired thickness of the laminate was obtained. Then this laminate was compressed in compression molding machine at 30 bars. The laminate was cured at room temperature for twenty four hours. Delamination specimens of dimensions $150 \mathrm{~mm}$ x $24.4 \mathrm{~mm}$ x $6 \mathrm{~mm}$ were cut from the composite 
panels of dimension $250 \mathrm{~mm} \times 250 \mathrm{~mm} \times 6 \mathrm{~mm}$. A $25 \mathrm{~mm}$ notch was machined at the straight sided edge of the sample. Aluminum hinges were attached on the sample to facilitate application of the load (Figure 3), and same procedure was adopted to fabricate the specimens toughened with MWNT.

\subsection{Double Cantilever Beam Testing}

The DCB test evaluates the critical strain energy release rate, $\mathrm{G}_{\mathrm{IC}}$ in which the crack propagates perpendicular to the loads. The critical strain energy release rate $\mathrm{G}_{\mathrm{IC}}$ can be calculated by modified beam theory

$$
\begin{array}{r}
\mathrm{G}_{\mathrm{Ic}}=\mathrm{P}_{\mathrm{c}}{ }_{1} 1 / 2 \mathrm{~B}(\mathrm{dC} / \mathrm{da}) \\
\mathrm{C}=\delta / \mathrm{P}
\end{array}
$$

Where, $\mathrm{P}_{\mathrm{c}}$ is the critical load, $\mathrm{B}$ is the width, $\mathrm{C}$ is compliance, $\delta$ is displacement and a is the crack length. Determining the strain energy release rate as:

$$
\mathrm{G}_{\mathrm{IC}}=3\left(\mathrm{~A}_{1} \mathrm{~A}_{2}^{2}\right) / 2 \mathrm{w}
$$

The two constants $A_{1}$ and $A_{2}$ can be obtained from the experimental data by means of linear regression.

A displacement controlled tensile test machine produced loads that were perpendicular to the interlaminar plane of failure. The edges of the specimen (Figure 3) was coated with a white correction fluid and marked for a clear reading of crack length. A $25 \mathrm{~mm}$ long notch was machined at the straight edge and a sharp razor blade was inserted at the slot and was hammered with a wooden mallet to negate any resin rich areas in front of the notch.

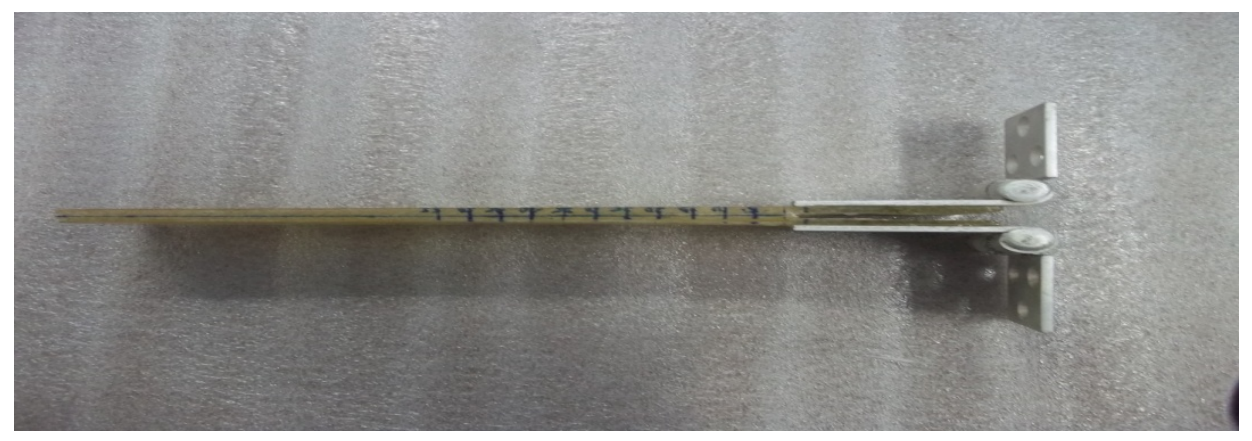

Figure 3. DCB specimen with aluminum hinges

\section{Results and Discussion}

\subsection{Mode-I Delamination}

A number samples of two different orientation were fabricated namely 0/90 and 0 degrees. Multi walled carbon nano tubes (MWNT) were dispersed in three different percent by weight and were compared to DCB samples without the presence of MWNT (Table 1). The delamination tests were performed on a $30 \mathrm{kN}$ displacement controlled tensile test machine with a cross head speed of $5 \mathrm{~mm} / \mathrm{min}$. The values of strain energy release rate

\begin{tabular}{|c|c|c|c|c|c|c|c|}
\hline \multirow{2}{*}{ Layup } & \multirow{2}{*}{$\begin{array}{l}\mathrm{G}_{\mathrm{IC}} \\
\mathrm{J} / \mathrm{m}^{2}\end{array}$} & \multicolumn{3}{|c|}{$\begin{array}{l}\mathrm{G}_{\mathrm{IC}} \text { With Per cent MWNT Infusion } \\
\mathrm{J} / \mathrm{m}^{2}\end{array}$} & \multicolumn{3}{|c|}{ Per cent Improvement in $\mathrm{G}_{\mathrm{IC}}(\%)$} \\
\hline & & 1 & 3 & 5 & 1 & 3 & 5 \\
\hline Cross Ply & 920.840 & 1150.067 & 1335.230 & 1389.900 & 20.35 & 44.98 & 51.10 \\
\hline 0 Degree & 680.750 & 850.953 & 987.087 & 1050.500 & 25.14 & 45.15 & 54.41 \\
\hline
\end{tabular}
were obtained from the load displacement curves by using a linear least squares regression analysis (Equation 3).

Table 1. $\mathrm{G}_{\mathrm{IC}}$ values of virgin samples and MWNT toughened samples and percent improvement

The quantitative resistance to Mode-I delamination can be precisely evaluated by using DCB delamination analysis. The critical strain energy release rate was calculated by fitting the experimental data to a known slope and the values of the strain energy release rate are shown in Table 1. And from the table, it is evident that there was a significant improvement in the strain energy release rate. 


\subsection{SEM Analysis}

The macroscopic appearance of fracture and mechanical properties depend upon which of these mechanisms dominate the overall fracture process. In particular, the following failure mechanism is of special importance: 1 . matrix deformation and fracture, 2. fiber/matrix debonding, 3. fiber pull out and 4. fiber fracture.

All these mechanisms consume energy and contribute to toughness of the composite. Which of them, and to what an extent, they actually occur during the failure of the material and this depends largely on the properties of the three microstructural elements of the composite namely: matrix, fiber and interphase and on the geometrical arrangement and form of the reinforcing components. To study the fracture surface details at higher magnification, smaller specimens are required from the fracture area and were viewed through Scanning Electron Microscope. Within each ply one can find fiber brakage (translaminar fracture) and fracture along fibers (intralaminar fracture). A third types of fracture can occur between individual laminea of equal or different fiber orientation. Several broken samples were cut from the specimens and were examined under scanning electon microscope. These samples were coated with gold and care must be taken by operator to clean the specimens from dust particles prior to SEM studies, using a dry air pressure device. The poorly coated regions and the dust particles which remain on the samples after cleaning, appear on the area to be photographed. They usually give rise to charging effects and poor quality photos.The interlaminar failures of the Mode-I samples were chracterised by fiber brakage, debonding and matrix cracking. The failed samples were examined using a high resolution Carl Zeiss electron microscope. Figures 6-11 illustrate the typical failure of Mode-I samples.

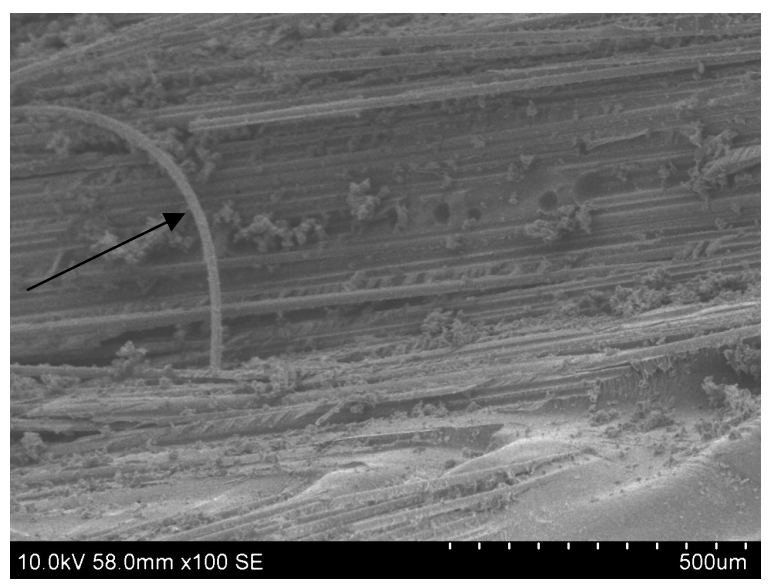

Figure 6. Mode-I DCB sample with fiber brakeage indicated by arrow

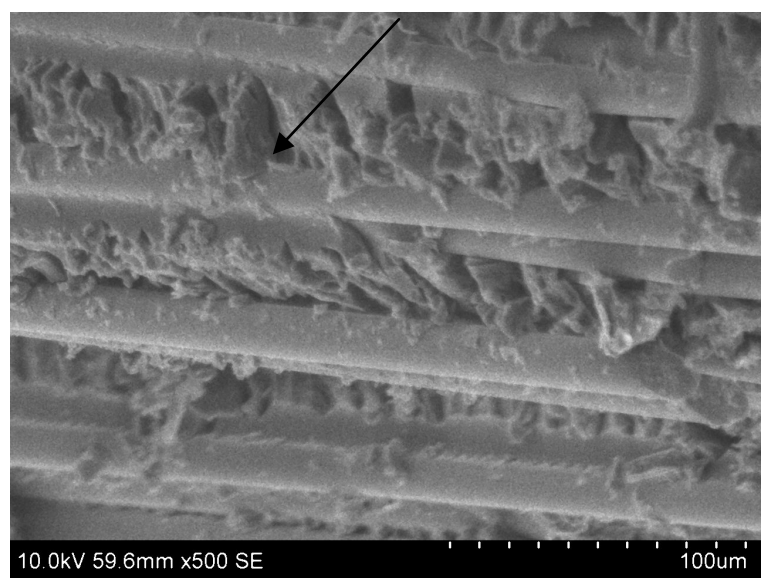

Figure 7. Mode-I sample with cusp formation indicated by arrow 


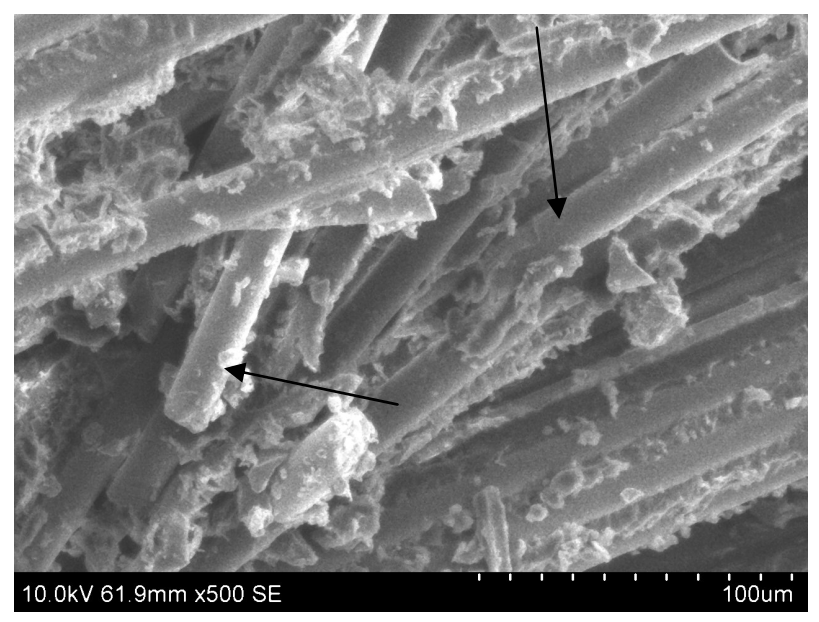

Figure 8. Sample with broken bundels of fiber

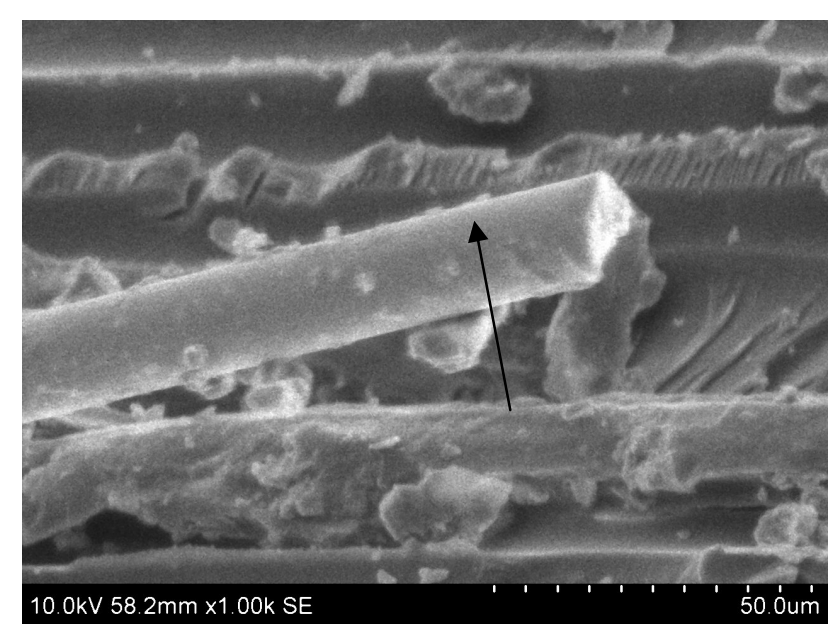

Figure 9. Fiber pull out and matrix failure

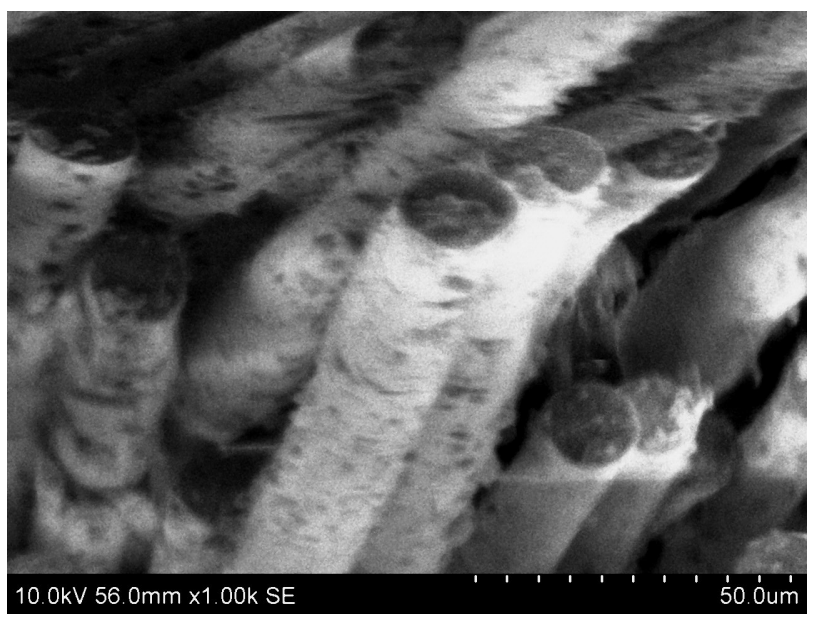

Figure 10. Dense network of fiber stubs 


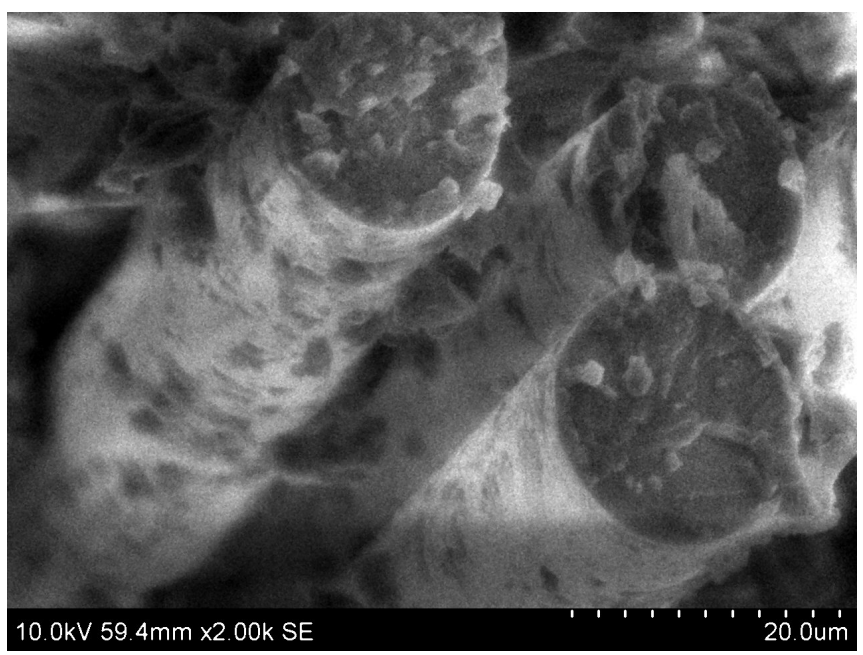

Figure 11. Evidence of spheroid morphology

The reason for differences in the fracture toughness data can be found in the various failure mechanisms of the polymer matrix and the composite, leading to more or less energy absorbtion during the breakdown of the composite under different loading conditions. Fractographic analysis using scanning electron microscope is of great value in this respect. From the fractured samples small specimens near the fracture surface (Figures 6-11). Samples tested under exteremes of crack opening velocities. At low crack-tip displacement (Purslow, 1988) rates, a highly stable crack growth would be present, while no distinction can be made between the fracture surface of the broken samples under very low and high crack opening velocities which could be calculated on the basis of: 1. degree of elongation of streched matrix tips and 2. share of platically deformed matrix per unit fracture surface. The details of matrix surface sites include the ribbons (Figure 6), cusps (Figure 7) can be seen and in addition one finds broken fiber ends (Figure 9) and spherodic fiber ends (Figure 11) which is typical of Mode-I delamination failures.

\section{Conclusions}

Three weight percent MWNT toughened glass fiber/epoxy were successfully manufactured using a wet-lay up technique. The Mode-I delamination tests were conducted to characterize $\mathrm{G}_{\mathrm{IC}}$ and examine the influence of influence of toughening by MWNT. The tests showed that 0 degree ply ahowed an improvement of $20 \%$ over the samples without MWNT infusion while the $5 \%$ infusion of MWNT showed $54.10 \%$ improvement for $0 / 0$ layup. While for the 0/90 layup the five percent infusion of MWNT showed an improvement of $51.10 \%$.

The sem micrographs of the fracture surface were taken to understand the fracture surface. The zoom out pictures of $1 \%$ MWNT infusion showed ribbon formation, while $3 \%$ infused surface showed a series of cusps formation. Another zoom out micrograph showed a stubs of broken fibers and spherodic surface with a crazing. Further work on Mode-I delamination studies would be conducted by varying several orientations and increasing the percentages of Multi Walled Carbon Nano tubes infusion into the resin.

\section{Acknowledgements}

The authors greatfully acknowledge the facilities provided by Mr. Aman Ullah Khan, test manager at CIPET, Guindy for providing the sem micrigraphs and Dr. P. Velmurgan, Head Compositeis testing facilities, IIT(M).

\section{Refrences}

Collins, P. G., \& Avouris, P. (2000). Nano tubes for electronics. Sci. Am., 283(6), 62. http://dx.doi.org/10.1038/scientificamerican1200-62

Fan, Z., Hsio, K. T., \& Advani, S. (2004). Exparimaetal investigation of dispersion during flow of multi-walled carbon nano tube/polymer suspension in fiberous porous media. Carbon, 42(4), 871. http://dx.doi.org/10.1016/j.carbon.2004.01.067

Fieder, B., Gojny, F. H., Wichmann, M. H. G., \& Bauhofer, W. (2004). Can nano tubes be used to sense damage in composites. Ann. Chim. Sci. Mat., 29(6), 81. http://dx.doi.org/10.3166/acsm.29.6.81-94 
Fielding, J. C., \& Jacques, A. (2004). Vacuum infusion processes for nano-modified for aerospace resins. In proceedindgs of the SAMPE international symposium.

Gilbert, E. N., \& Hayes, B. S. (2003). Interlayer toughened unidirectional carbon prepreg systems: effect of $\begin{array}{llllll}\text { preformed } & \text { particle morphology. } & \text { Composites }\end{array}$ http://dx.doi.org/10.1016/S1359-835X(02)00141-0

Hasio, K. T., Alms, J., \& Advani, S. G. (2003). Use of epoxy /multi walled carbon nano tubes as adhesives to join graphite fiber reinforced polymer composites. Nanotechnology, 14, 791. http://dx.doi.org/10.1088/0957-4484/14/7/316

Kim, P., Shi, L., Majumdar. A., \& McEuen, P. L. (2001). Thermal tranport measurements of individual multiwalled carbon nano tubes. Phys Rev Lett., $87(21), \quad 5502$. http://dx.doi.org/10.1103/PhysRevLett.87.215502

Majid. R. Ayatillahi \& Mahmod. M. (2011). Mechanical and Electrical Properties of Epoxy/MWNT/Nanoclay. Iranian Polymer Journal, 20(10), 835.

Meguid, S. A., \& Sun, Y. (2004). On the tensile and shear strength of nano reinforced composite interfaces. Mater. Des., 25, 289. http://dx.doi.org/10.1016/j.matdes.2003.10.018

Morais, A. B. (2003). Double cantilever beam testing of multidirectional laminates. Composites Part A, 34(12), 1135. http://dx.doi.org/10.1016/j.compositesa.2003.08.008

Mouritz, A. P., Baini, C., \& Hersberg, I. (1999). Mode-I interlaminar fracture toughness properties of advanced textile fiber glass composites. Composites Part A, $30(7), \quad 859$. http://dx.doi.org/10.1016/S1359-835X(98)00197-3

O'Brien, T. K. (1988). Interlaminar fracture toughness: the long and winding road to standardisation. Composites Part B, 29(1), 57. http://dx.doi.org/10.1016/S1359-8368(97)00013-9

Purslow, D. (1988). Fractography Study of Fiber Reinforced Thermoplastics Part 2. Composites, 18. 365. http://dx.doi.org/10.1016/0010-4361(87)90360-0

Robinson, P \& Song, D. Q. (1999). Delamination growth during fatigue of advanced polymer composites. Journal of Composite Materials, 33, 1554.

Rugg, K. L., \& Cox, B. N. (2002). Mixed mode delamination of polymer composite laminates reinforced through thickness by z-fibers. Composite Part A, 33(2), 177. http://dx.doi.org/10.1016/S1359-835X(01)00109-9 